\title{
DESCRIPCIÓN DEL MS. 80 DE AL-ZĀWIYA AL-ḤAMZAWĪYA ${ }^{1}$
}

\author{
Ahmad AlKuWAIFI - Mònica Ríus \\ Universidad de Barcelona
}

\section{INTRODUCCIÓN}

La Zāwiya Hamzawīya forma parte de las bibliotecas marroquíes descritas en Les bibliothèques au Maroc por Latifa Benjelloun-Laroui ${ }^{2}$. Anteriormente, Muhammad al-Mannūnī había publicado un inventario de los fondos de la biblioteca entre los que se hace referencia al manuscrito 80 aunque sin especificar todo su contenido ${ }^{3}$. En este mismo artículo introducía un resumen de la historia de la Zāwiya haciendo hincapié en los principales copistas que trabajaron en ella, así como en las expediciones locales y extranjeras que consultaron sus manuscritos ${ }^{4}$. Por otra parte, H. P. J. Rénaud publicó, ya en el año 1934, «Un prétendu catalogue de la Bibliothèque de la Grande Mosquée de Fès" ${ }^{5}$ donde dejaba claro que el catálogo estudiado no era de la Gran Mezquita de Fez sino de la zäwiya en cuestión. Añadía un índice general de los manuscritos de esta biblioteca, incluida la maŷmü'a que nos ocupa, aunque tampoco detallaba todo su contenido. Es por ello que hemos creído interesante y útil desglosar más a fondo los materiales incluidos añadiendo, a su vez, un pequeño estudio de los mismos.

\section{DESCRIPCIÓN DEL MANUSCRITO}

El ms. n. ${ }^{\circ} 80$ de la Zāwiya Ḥamzawīya es una maŷmū'a que contiene 427 folios numerados correlativamente aunque con algunos errores: algunas veces

\footnotetext{
${ }^{1}$ Este trabajo ha sido realizado en el marco del Programa de Investigación "Astronomía teórica y tablas astronómicas en al-Andalus en los siglos XII-XIV» del Departamento de Árabe de la Universidad de Barcelona, subvencionado por la D.G.I.C.Y.T.

${ }^{2}$ París, 1990, 288-295.

${ }^{3}$ "Maktabat al-Zāwiya al Hamzīya", Tịtwān VIII (1963), 97-177 [en adelante Mannūnī]. En dicho artículo, se le asigna el número 157.

${ }^{4}$ Asimismo, 'Abd al-Salām b. Sūda cita en su Dalī mu'arrij al-Magrib al-Aqșà (Tetuán, 1950, 35-36) un libro de Abū Muhammad 'Abd Allāh b. 'Umar b. 'Abd. Al-Karīm b. Abīi Bakr al-'Ayyāšī

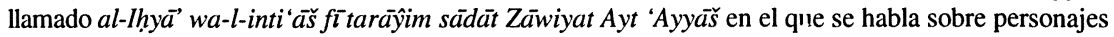
ilustres relacionados con la misma.

${ }^{5}$ Hespéris XVIII (1934), 76-99 [en adelante Rénaud 1].
} 
faltan folios (en el microfilm) y otras se repite la numeración. Hemos trabajado a partir de un microfilm, por lo que desconocemos exactamente el tamaño y otras peculiaridades del manuscrito original, aunque sí se puede comprobar que está en bastante buen estado. Está escrito con grafía magrebí y la letra, en general, es clara.

La mayor parte del conjunto corresponde a un mismo copista cuyo nombre completo desconocemos; sin embargo, en el folio 425 da el nombre y la fecha de muerte de su padre, 'Umar b. Aḥmad b. Abī l-Qāsim al-Šarîf (m. 1005/15961597). También cita repetidamente el nombre de un tío materno, que utiliza como fuente, llamado 'Abd al-Wāḥid b. Aḥmad b. Muḥammad b. al-Ḥasan al-Ḥasanî e incluye una jutba en prosa rimada de su tío paterno, el alfaquí Muhammad b. Muhammad b. Balqāsim al-Ḥasanī (m. 988/1580) ${ }^{7}$. El copista parece tomar parte activa en la elección de los textos ${ }^{8}$ aunque no queda claro cuál es el criterio adoptado.

\section{CONTENIDO DEL MANUSCRITO}

\section{Folio}

1 - Índice simplificado del contenido de la maŷmū'a.

- Esquema, muy rudimentario, de un cuadrante o instrumento parecido.

2 - Texto anónimo, con letra de un copista diferente, que hace referencia a las mansiones lunares ${ }^{9}$.

\footnotetext{
${ }^{6}$ Sobre este autor véase, en esta misma $m a \hat{m} m u^{-} a$, los folios 3, 4, 339, 407-411 y 426 . En este último folio se dice que murió en el 1003/1595, pero, según Ibn al-Qāḍī, la fecha de su muerte tuvo lugar el 998/1590. Cf. Ibn al-Qāḍī, Durrat al-hiŷă fí̄asmā' ' al-riŷäl, Rabat, s/f., III, n. ${ }^{\circ}$ 1096, 140-142.

${ }^{7}$ Mannūnī, p. 157.

${ }^{8}$ Por ejemplo, en el folio 197, precisa: «[...] He querido fijar aquí una parte de lo que necesito del Zî̀ de Ibn 'Azzūz [...]".

${ }^{9}$ Para una información detallada de las mansiones lunares véase el artículo «al-Manāzil» de Kunitzsch, P., en Encyclopédie de l'Islam. Nouvelle édition, Leiden, 1960-1997 [en adelante EI ${ }^{2}$ ], VI, 358-360.
} 
3 - Ta'rïf Abü [sic]-l-Șalt ${ }^{10}$, șähib Risālat al-asturläb. En esta biografía se hace constar que Umayya b. 'Abd al-'Azīz b. Abī-l-Șalt, originario de Denia, vivió un tiempo en Sevilla y, posteriormente, se trasladó a Oriente, donde visitó la mayor parte de sus ciudades, para acabar instalándose en la corte del emir Abū-l-Ṭāhir Yahyà b. Tamīm b. alMu'izz b. Bādīis ${ }^{11}$, en Mahdīya. Compuso la obra llamada Risälat al'amal bi-l-asturlāb (Tratado sobre el uso del astrolabio). Escribió también un libro sobre Egipto y sus maravillas ('aŷa'ib) donde menciona a los filósofos, médicos y literatos que encontró en ese país $^{12}$. Compuso una obra histórica, basada en el Tärīj Ifríqiya de Abū Ishāa al-Raqīq ${ }^{13}$, centrada en los antecesores de su anfitrión, así como en sus descendientes más directos (su hijo 'Alī y su nieto al-Hạan ${ }^{14}$ ). De entre sus obras literarias destaca el Kitāb al-ḥadīqa (Libro del Jardín) donde incluye poemas de algunos de sus contemporáneos. De sus obras filosóficas, menciona el Taqwin al-dihn (Rectificación de la mente) ${ }^{15}$. Finalmente, es autor del Kitāb al-adwiya al-mufrada (Libro de los medicamentos simples). Destacó, asimismo, en la baläga y en la fașāha. Fue discípulo del excelente literato Abū-l-Hiasan 'Alī b. 'Abd al-Mugnī al-Hụșīi, entre otros; muestra de ello son los poemas incluidos en su Târ $\vec{j}$ antes mencionado. El copista dice haber tomado

\footnotetext{
${ }^{10}$ En esta noticia biográfica de Abū l-Șalt (m. 529/1134) no se menciona que estuvo en prisión, en Alejandría, tras haber fracasado en un oneroso intento de sacar a la superficie un barco cargado de plata que se había hundido en el mar. Sobre este autor véase también: Ibn Abī 'Ușaybi 'a, 'Uyūn al-anbä' fī tabaqāt al-attibä, Beirut, 1987, 86-100; Brockelmann, C., Geschichte der arabischen Litteratur. Supplementband, Leiden, 1937-1942, [en adelante GALS] I, p. 889; $E I^{2}$ I, p. 153 (J. M. ${ }^{\text {a }}$ Millàs Vallicrosa); Comes, M., Ecuatorios andalusies, Barcelona, 1991, 140-141; Fierro, M. y otros, Historia de Autores y Transmisores Andalusíes. Repertorio biobibliográfico de sabios andalusíes, 711-1492, en curso de publicación [en adelante HATA].

${ }^{11}$ Emir zīrí, reinó entre el 509/1116 y el 515/1221. Cf. Laroui, A., Historia del Magreb desde los orígenes hasta el despertar magrebi, Madrid, 1994, p. 387.

${ }^{12}$ La Risala Mișrīya. Cf. Prémare, A. L. de, "Un Andalou en Egypte à la fin du XI siècle: Abū-1Șalt de Denia et son Epître Egyptienne», Mélanges de l'Institut Dominicain d'Études Orientales 8 (1964-66), 179-208.

${ }^{13}$ Célebre historiador de época zĩrí, murió después del 418/1027-8. Cf. EI ${ }^{2}$ III, p. 927 (M. Talbi). No hemos encontrado otras menciones en las que se indicara que Abū-l-Şalt utilizó a Ibn Raqīq como fuente para su $T a \bar{r} \vec{\jmath}$.

14 'Alī sucedió a su padre y reinó hasta el 543/1148, año en el que, a su vez, le sucedió al-Ḥasan; éste reinó hasta la fecha de su muerte, ocurrida en el 566/1171.

${ }^{15}$ Editado y traducido por González Palencia, A., Rectificación de la mente. Tratado de lógica por Abusalt de Denia, Madrid, 1915. Cf. HATA.
} 
este ta' rîf de su tío materno, 'Abd al-Wāḥid b. Aḥmad b. Muḥammad b. al-Ḥasan al-Ḥasan̄̄, quien, a su vez, lo copió del dorso de la Risāla asturläb ̄̄ya de Abū 1-Șalt.

4 - Anotación de varias fechas: la de la boda de Muḥammad b. 'Umar alHasanī ${ }^{-16}$ a mediados de $\underline{D} \bar{u}-l-h i \hat{y} \hat{y} a$ del 999 (finales de septiembre de 1591); la del nacimiento de una hija, en Siŷilmāsa, el martes 6 de Ša bān del 1008 (11 de febrero de 1600); y la de un viaje a Marrākuš en Rabī‘ al-Awwal del 1009 (agosto-septiembre de 1600); tras las cuales se citan unos versos de Ibn al-Jatīib al-Salmānī ${ }^{17}$ dirigidos a algunos de sus šuyüj y que están incluidos en una obra llamada

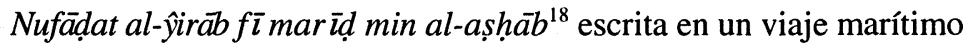
de retorno desde el Magrib a al-Andalus ${ }^{19}$.

- También da indicaciones sobre la entrada del mes de enero en 3 fechas distintas. Utiliza, al parecer, tres sistemas de numeración: la cifra escrita como palabra, la numeración arábiga y las cifras de Fez.

- miércoles, 29 Rabī' II, 1003 [1 de enero de 1595].

- viernes, 11 Ŷumāda I, 1004 [1 de enero de 1596].

- domingo, 3 Ŷumāda II, 1006 [1 de enero de 1598$]^{20}$.

\footnotetext{
${ }^{16}$ Muhammad b. 'Umar es hermano del copista. Véase fol. 425 de esta misma maŷmü‘ $a$.

${ }^{17} \mathrm{Ibn}$ al-Jatîb (713/1313-776/1375). Sobre este autor véase $E P^{2}$ III, 859-861 (S. Gibert).

${ }^{18}$ El título de la obra que aparece normalmente es Nufädat al-yîrä̉ fi 'ulälat al-igtiräb. Cf. Brockelmann, C., Geschichte der arabischen Litteratur, Weimar, 1898-1902 [en adelante GAL], II, p. 262; GALS, II, p. 372; Derenbourg, H., Les manuscrits arabes de l'Escurial, París, 1884-1928, III, p. 261 (n. ${ }^{\circ}$ 1755); Viguera, M. J., "La cultura nazarí y sus registros históricos, bibliográficos y geográficos", Estudios nazaries, ed. C. Castillo, Granada, 1997, p. 187 y nota 76. Aḥmad Mujtār al-'Abbādī editó este texto en El Cairo en 1968.

${ }^{19}$ Este viaje de Ibn al-Jatîb, durante el cual se entrevistó con los jefes tribales de la región, tuvo lugar en el año 760/1359. Cf. Shatzmiller, M., L'historiographie mérinide, Leiden, 1982, p. 135, y Viguera, M." J., "Ibn al-Jatīib visita el monte de los Hintāta", Homenaje al Prof. José María Fórneas (Granada, 1995), 645-659.

${ }^{20}$ Nos ha parecido de interés calcar la forma original en que aparecen las fechas 1004 y 1006 . En ambas, el trazado del valor "1000" difiere ligeramente de las variantes utilizadas en las cifras de Fez. Además, en la segunda, fusiona dos sistemas numéricos, es decir, utiliza esta nueva variante del valor "1000" seguida de la cifra arábica "6" (fig. 1). Sobre estas cifras véase también Labarta, A., y Barceló, C., Números y cifras en los documentos arábigohispanos, Córdoba, 1988, p. 20; Lamrabet, D., Introduction à l'histoire des mathematiques maghrebines, Rabat, 1994, p. 179 [en adelante Lamrabet].
} 


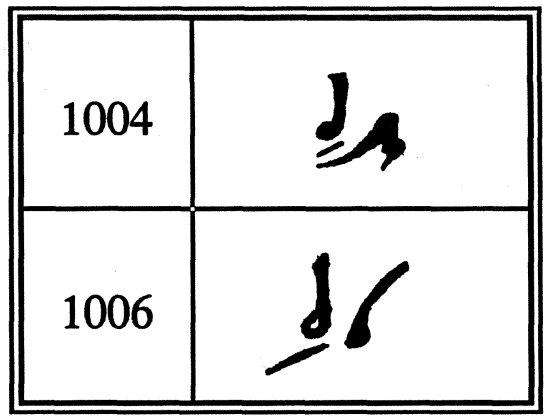

Figura 1. Cifras que aparecen en el folio 4

- Hoja suelta e incompleta en la que se hace mención de los nombres de doce de las veintiocho mansiones lunares. El texto confunde Turayyā primero con al-Nath y, más tarde, con al-Butayn. También da el nombre "griego" de Qalb-al-asad, que identifica con Süliqūs (sic por Basilicus) y la versión latina de al-Kawkabān al-Nayyirān que identifica con al-Sahä'ib y al-Himärān (y que evidentemente no es latín sino árabe).

5bis - Coordenadas geográficas de La Meca, latitud $(\varphi) 21 ; 40^{\circ}$ y longitud $(\lambda)$ $77^{\circ}$, aunque también se dice $79^{\circ}$, y Tadlā, $\varphi 32^{\circ}$ y $\lambda 24 ; 40^{\circ 21}$.

6 - al-'Ayyāšsi ${ }^{22}$ : instrucciones para el uso de los números arábigos e hindúes (clasificados en unidades, decenas, centenas y millares) que, según el copista, aparecerán a lo largo del libro.

\footnotetext{
${ }^{21} \mathrm{La}$ latitud $\left(\varphi=21 ; 40^{\circ}\right)$ y longitud $\left(\lambda=77^{\circ}\right)$ que cita para La Meca son muy usuales. No hemos encontrado, en cambio, ninguna fuente que hable de una $\lambda 79^{\circ}$. Las coordenadas modernas de Tadlā son $\varphi 32 ; 34^{\circ}$ y $\lambda 355 ; 42^{\circ}$; el valor que da el texto coincide con el de Ibn al-Raqqām, quien establece $32^{\circ}$ para la latitud y $24^{\circ}$ para la longitud. Cf. Kennedy, E. S., y M. H., Geographical Coordinates of Localities from Islamic Sources, Frankfurt am Main, 1987 [en adelante Kennedy], 226 y 339; 'Abdurrahmān, M., El cálculo de las longitudes planetarias en el Zî̀ al-Šāmil fî tahdīib al-kāmil de lbn al-Raqqüm [en adelante Ibn al-Raqqäm], tesis mecanografiada, Barcelona, 1996, p. 327.

${ }^{22}$ Abū Sălim al-'Ayyāšì (m. 1090/1679), personaje relacionado con la Zāwiya, fue discípulo de alFāsī y al-Dādīsī y leyó las obras de al-Ŷădirī. $C f . E I^{2}$ I, p. 818 (M. Ben Cheneb \& C. Pellat); LéviProvençal, E., Les historiens des Chorfa, Paris, 1922, 262-264; Rénaud 1, p. 82; GALS II, p. 711.
} 
7-87 - Abū 1-Șalt: Kitāb fī-l- 'amal bi-l-asturlāb $b^{23}$. Tratado sobre el uso del astrolabio que contiene 98 capítulos $(b \overline{a b})$ [fols. 7-66] y 27 qawl fi-l-imtihānāt [fols. 66-82] destinados a hacer todo tipo de comprobaciones de cada una de las partes del astrolabio, seguidos de 3 capítulos (bāb) [fols. 83-87] numerados del 28 al 30.

[28sic]88 - Fragmento anónimo de un texto sobre el movimiento del $\mathrm{Sol}^{24}$.

$89-$ Folio que contiene 4 tablas $^{25}$ :

- Superior derecha: tabla para calcular la feria con la que empiezan los años (al-sanawät al-mabsütāt [sic]) o ciclos de 30 años (al-sanawāt al-maŷmü'a) musulmanes.

- Inferior derecha: tabla para calcular la feria con la que empieza un mes musulmán.

- Superior izquierda: tabla con las posiciones de los apogeos del Sol y los 5 planetas para la Hégira (aunque en margen indica que corresponde al año 985H. [1577-78]).

- Inferior izquierda: tabla de ascensiones oblicuas (para Tremecén $\varphi=35^{\circ}$, Túnez, $36 ; 40^{\circ}$ [o $34 ; 40^{\circ}$ ] y Fez, $33 ; 40^{\circ}{ }^{26}$ ) y rectas. A pesar del título, lo que ofrece son los tiempos de orto de los 12 signos zodiacales para cada una de estas tres latitudes, así como para la latitud $0^{\circ}$ (ascensión recta).

90 - Tabla de movimiento medio del Sol y la Luna en días, meses, años mabsüta (de tres en tres) y años maŷmü' $a$. El radix (așl) es para Tremecén.

91 - Tabla de movimiento medio de la anomalía de la Luna y los nodos lunares. Aṣl para Tremecén, Fez, Marrākuš y Túnez.

\footnotetext{
${ }^{23}$ Millàs, J. M.', Assaig d'història de les idees físiques i matemàtiques a la Catalunya medieval, Barcelona, 1931, 77-80; Rénaud 1, p. 86; Mannūnī, p. 155; ms. Berlín (Ahlwardt, V, 232-4, n..$^{\circ}$ 5798, que es el estudiado por Millàs); ms. Leiden Or., n. 556 (2); HATA.

${ }^{24}$ Rénaud I, p. 87: “kalām "alà harakat al-šams".

${ }^{25}$ Rénaud I, p. 86: «ŷadāwil fïl-ta'd $i l ’$ '.

${ }^{26} \varphi=35^{\circ}$ es un valor usual para Tremecén; $\varphi=36 ; 40^{\circ}$ (o $34 ; 40^{\circ}$ ) se encuentra citado únicamente por Ibn al-Raqqām, quien se acerca mucho al valor moderno, $36^{\circ} 50^{\prime} ; \varphi=33 ; 40^{\circ}$ es una latitud aplicada a Fez en varias fuentes medievales, entre ellas, Ibn al-Raqqām. $C f$. Kennedy 355, 362 y 118, respectivamente; Ibn al-Raqqäm, 327-329.
} 
92 - Tabla de movimiento medio de Saturno y Júpiter.

93 - Tabla de movimiento medio de Marte en longitud y de Venus en anomalía.

94 - Tabla de movimiento medio de Mercurio en anomalía, y de la ecuación del Sol (valor máximo $=2 ; 0^{\circ}$ ) y de la Luna en función de la anomalía (valor máximo $=4 ; 50^{\circ}$ ).

$95 \quad$ - Tabla de la velocidad de la Luna (sin rellenar).

- Tabla de las estaciones y de las retrogradaciones de los planetas

96 - Tabla de la ecuación del centro de los 5 planetas.

\begin{tabular}{|c|c|c|c|c|c|}
\hline $\begin{array}{c}\text { VALORES } \\
\text { MÁX. }{ }^{27}\end{array}$ & SATURNO & JÚPITER & MARTE & VENUS & MERCURIO \\
\hline Ec. centro & $6 ; 31 / 6 ; 31^{*}$ & $5 ; 15 / 5 ; 15^{*}$ & $11 ; 38 / 11 ; 25^{*}$ & $2 ; 0 / 2 ; 24 *$ & $4 ; 0 / 3,02^{*}$ \\
\hline Ec. anomalía & $6 ; 12 / 6 ; 36^{*}$ & $11 ; 09 / 11 ; 36^{*}$ & $41 ; 40 / 46 ; 59 *$ & $47 ; 39 / 47 ; 15^{*}$ & $22 ; 50 / 23 ; 53^{*}$ \\
\hline
\end{tabular}

$97 \quad$ - Tabla de longitudes y latitudes geográficas.

98 - Tabla de la ecuación de la anomalía (véase cuadro superior): es una tabla extraña que parece calculada en función de la anomalía del planeta sin tener en cuenta su excentricidad. Por otra parte, los valores llevan la indicación burūŷy (signos) y daraŷ (grados) en lugar de daraŷy y daqä’ iq (minutos).

${ }^{27}$ Valores máximos de la tabla comparados con los valores de Ptolomeo (indicados con asterisco). Cf. Pedersen, O., A Survey of the Almagest, Odense, 1974, 425-429. 
99 - Tabla de eclipses de doble entrada: da el número de dígitos eclipsados del Sol y de la Luna en función del $b u^{\prime} d$ (distancia al nodo comprendido entre $1^{\circ}$ y $12^{\circ}$ para la Luna y entre $1^{\circ}$ y $9^{\circ}$ para el Sol) y de la velocidad diaria de la Luna (comprendida entre $12^{\circ}$ y $\left.15^{\circ}\right)^{28}$.

100 - Fragmento, con caligrafía distinta, sobre al-Turayyā tomado de un libro de al-Umawī al-Qurtubîi ${ }^{29}$.

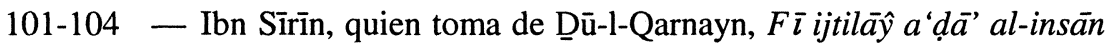
min qarni-hi ilà qadami-hi ${ }^{30}: 19$ capítulos sobre "reflexología» de las diferentes partes del cuerpo humano.
104-114 - Ibn al-Bannā'31, Kitā̄b min 'ilm al-awqāt wa-l-ḥisā̄b ${ }^{32}$. Consta de 15 capítulos.

114 - Fragmento del Kitäb al-tamara ${ }^{33}$.

115-116 - Tabla con previsiones de eclipses. Aparecen años de la Hégira (desde el 984 hasta el 1192), pero con referencia a meses solares.

Varios capítulos de obras dispersas sin mención del autor:

\footnotetext{
${ }^{28}$ Goldstein, B. R., "Lunar Velocity in the Middle Ages: A Comparative Study», en Casulleras, J., y Samsó, J. (eds.), De Bagdad a Barcelona, Barcelona, 1996, I, 181-194.

${ }^{29}$ Al-Umawī al-Qurtubī (m. 602/1206). Véase Réanud I, p. 87; Forcada, M., "Los libros de anwa en al-Andalus", El Legado Científico Andalusí, Madrid, 1992, 111-112; ms. 941 de la Biblioteca de El Escorial.

${ }^{30}$ En GALS I (p. 102) aparece citado el tradicionalista Ibn Sīrin, muerto en 110/728, pero la identificación no es segura. Otra obra del mismo género es Ijtilāŷal-a'ḍă’ de Abū 'Abd Allāh Ŷa ‘far al-Șādiq, también citado en GALS I, 104. Rénaud I, p. 87: "tremblements du corps de l'homme».

${ }^{31}$ Sobre Ibn al-Bannā' (m. 721/1321) véase Lamrabet, p. 83; Suter, H., Die Mathematiker und Astronomen der Araber und ihre Werke, Amsterdam, 1981 (reimpresión de la edición de 1897) [en adelante Suter] n. ${ }^{\circ}$ 399, p. 162; Rénaud, H. P. J., "Ibn al-Bannā’ de Marrakech, șūfī et mathématicien (XIII'-XIV ${ }^{\mathrm{e}}$ s. J.C.)", Hespéris XXV (1938), 13-42; EI ${ }^{2}$ III, 753-754 (Suter \& Ben Cheneb); GALS II, 363-364.

${ }^{32}$ Podría ser el Qänūn fïma 'rifat al-awqāt bi-l-hisäb. Cf. Lamrabet, p. 84; Rénaud I, p. 87.

${ }^{33}$ Es decir, el Centiloquium del Pseudo-Ptolomeo.
} 
117-119 - Fragmento sobre el movimiento de los planetas ${ }^{34}$.

120-121 - Bābfī ma'rifat al-ayyām bi-layāli-hā.

122 - Faṣl fīma'rifat al-samt min qibal al-irtifä'.

123-124 - 'Abd al-Raḥmān al-Tāŷūrī al-Miṣrī al-Mālikî35: capítulo de su libro Dalä'il qiblat ahl al-Magrib. En el fol. 124 hay, además, un texto sobre la qibla de Ibn Hilāl estructurado en pregunta/respuesta, y una fä'ida sobre el mismo tema de Ibn al-'Arabī.

Estos dos folios, de lectura difícil, son de copista distinto al del resto de la obra.

125 - Tabla que da, con intervalos de $6^{\circ}$, los grados de la eclíptica que equidistan de los solsticios y que, por ello, tienen la misma declinación, arco diurno y nocturno y amplitud ortiva y occidua.

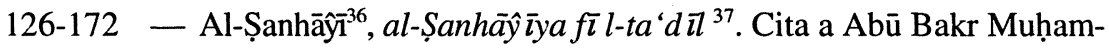
mad b. Yūsuf al-Sabtī ${ }^{38}$, Abū 1-Haŷȳâŷ Yūsuf al-Saqatī, Ibn $\mathrm{Habīib}^{39}, \mathrm{Ka}$ 'b al-Aḥbār ${ }^{40}$ e Ibn 'Āṣim ${ }^{41}$. El autor dice haber tomado esta última referencia de unos inmigrantes andalusíes que pretenden transmitirla de la obra original de Ibn 'Āṣim.

172-173 - Tres Qā'idas fī istijrāŷy al-āss, la última de las cuales incluye unos versos de al-Ṣagīr b. sìd ì Aḥmad b. al-Ḥâŷŷy.

${ }^{34}$ Rénaud 1, p. 87: “Ouvrage anonyme sur le déplacement des étoiles de première grandeur et autres questions de la science de la détermination astronomique des heures - ta'liffī tarh ì al-daräri ilà gayr dălika mimmä huwa fí 'ilm al-tawq ì mimmā yatülu” .

${ }^{35}$ Al-Tāŷūrī murió en el año 999/1590. Cf. GAL II, p. 358; Suter, n. ${ }^{\circ}$ 512, p. 200.

${ }^{36}$ Abū 'Abd Allāh Muhammad b. Abī-l-Hasan 'Alī al-Ṣanhāŷĩ estuvo relacionado con la Zāwiya. Cf. Rénaud, H. P. J., "Astronomie et astrologie marocaines”, Hespéris XXIX (1942), 62.

${ }^{37}$ Mannūnī, p. 156.

38 Astrónomo del s. XII. Cf. Mannūnī, M., Al-'Ulūm wa-l-ädāb wa-l-funūn 'alà 'ahd al-muwähhid in, 109-110; Lamrabet, p. 77.

${ }^{39}$ Véase fols. 185-197 de esta maŷmü' $a$ y las notas correspondientes.

${ }^{40} \mathrm{Ka}$ 'b al-Aḥbār, tradicionista de Yemen de origen judío, muerto en 32/652-3. Cf. EI IV, 330-331.

${ }^{41}$ Sobre este autor, muerto en 403/1013, véase Ibn 'Āșim, Kitäb al-anwä' wa-l-azmina -al qawl fi-l-šuhūr-, estudio, traducción y edición crítica por Miquel Forcada, Madrid, 1993. 
AQ. XIX, 1998

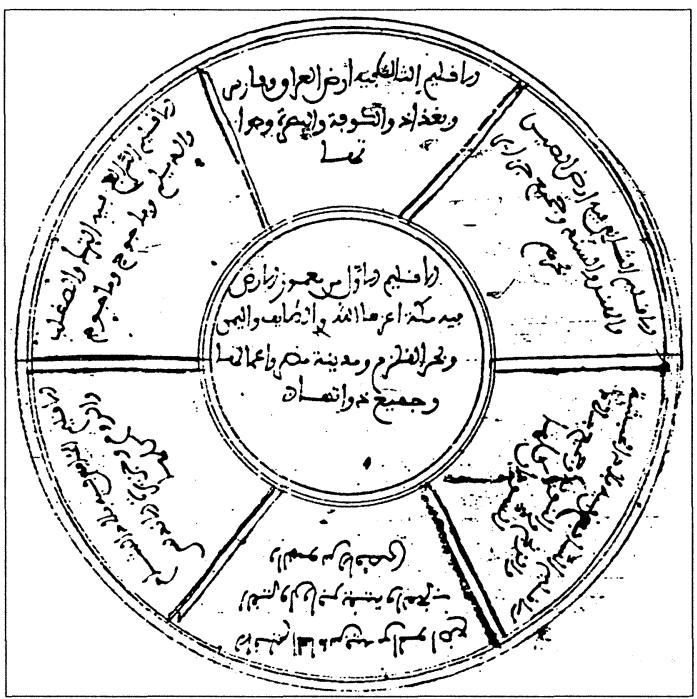

Figura 2. Esquema geográfico circular del folio 173.

A continuación, hay un esquema geográfico, dividido en siete climas, que sitúa La Meca en el centro (clima I) y los otros seis circundantes a ella ${ }^{42}$ (Fig. 2).

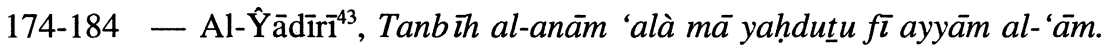
Calendario, glosa sobre un Taqy $\bar{d}^{44}$ de Ibn al-Bannā', readaptado a la latitud de Fez. Al final del fol. 176 y principio del 177 hay un

${ }^{42}$ Esta división del ecumene se corresponde con la de al-Zuhrī, quien, a su vez, lo toma de alFazārī. Al-Bīnūnī afirmaba que los persas dividieron el mundo, por reinos, en siete regiones (kišwārāt) y atribuyeron esta división a Hermes. El esquema de la maŷmü ‘ $a$ parece, pues, una «islamización" de los kišwārāt persas. Cf. Bramón, D., El mundo en el siglo XII. El tratado de al-Zuhrī, Barcelona, 1991, p. 18; Sadok, M. H., "Kităb al-Dja'rāfiyya», Bulletin d'Études Orientales XXI (1968), 43 y 297; Corbin, H., Corps spirituel et Terre céleste. De l'Iran mazdéen à l'Iran Shî̀ite, París, 1979, 43; al-Bīrūnī, Kitäb al-tafh ìm li-awä'il șinā'at al-tanŷ̀im, facsímil y trad. de R. Ramsay Wright, Londres, 1934, p. 142.

${ }^{43}$ Abū Zayd 'Abd al-Raḥman Muhammad al-Ŷādīrī nació en Mequínez en 777/1375 y murió en Fez, probablemente en 818/1416. Fue muwaqqit de la mezquita de al-Qarawīyīn. $C f$. Mannūnī, p. 156; Lamrabet, p. 114; Suter n. ${ }^{\circ} 424^{\text {a }}$, p. 172; GALS II, 218-219.

${ }^{44}$ Taqy ìd al-šuhür al-'aŷam ìya wa-mā yahdutu fï-hä. Cf. Lamrabet, p. 83. 
espacio en blanco y el texto salta del mes de febrero a julio. En la última página se indica la fecha de redacción de la obra: 15 de Ŷumādà II del 801 (23 de febrero de 1399).

185-197 - Kitāb al-nuŷūm ${ }^{45}$ de 'Abd al-Mālik b. Habīb ${ }^{46}$. Los dos últimos folios (196 y 197) faltan en el microfilm (no en la maŷmü‘ $a$ ). Paul Kunitzsch ${ }^{47}$ ha conseguido una copia de estos folios en los que también se hallaba el principio del texto siguiente.

197-202 - Dos capítulos de al-Zīŷ al-muwāfiq de Ibn 'Azzūz al-Qusantīn̄̄is . En el fol. 202, un copista, distinto al del resto del texto, indica el final del fragmento.

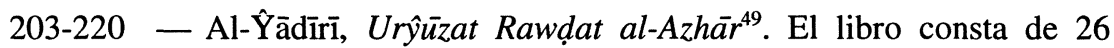
capítulos (incluyendo la introducción), con un total de 335 versos.

- En el margen del último folio (220) se dan varias coordenadas geográficas:

- La Meca: $\varphi$ 21;40 $\lambda 77^{\circ}$.

- La Ka'ba:(según Aḥmad b. al-Ḥāŷŷ) $\varphi 21^{\circ} ; \lambda 67^{\circ}$ (otros dicen $\left.77^{\circ}\right)$.

- Fez: $\varphi 23^{\circ} ; \lambda 24^{\circ}{ }^{50}$.

\footnotetext{
${ }^{45} \mathrm{P}$. Kunitzsch editó, tradujo al inglés y estudió este texto basándose en nuestro mismo manuscrito. Cf. Kunitzsch, P., «Abd al-Malik b. Habỉb's Book on the Stars", Zeitschrift für Geschichte der ArabischIslamischen Wissenschaften 9 (1994), 161-194; Mannūnī, p. 156.

${ }^{46}$ Sobre Ibn Habỉb véase EP III, p. 798 (Huici Miranda); Ibn Habỉb, Kitab al-Ta'r $\vec{y}$, estudio, traducción y edición crítica por J. Aguadé, Madrid, 1991; Ibn H̦abỉb, Kitäb Wasf al-Firdaws (La descripción del Paraíso), introducción, traducción y estudio por J. P. Monferrer, Granada, 1997, 14-25.

${ }^{47}$ Kunitzsch, P., "Abd al-Malik Ibn Habỉb's Book on the Stars (Conclusion)", Zeitschrift für Geschichte der Arabisch-Islamischen Wissenschaften 11 (1997), 179-188.

${ }^{48}$ Véase Mannūnī, p. 156 y nota 3; Samsó, J., “Andalusian Astronomy in $14^{\text {th }}$ Century Fez: $\mathrm{Al}$-Z $\bar{\jmath}$ al-Muwäfiq of Ibn 'Azzūz al-Qusantīin̄̄, Zeitschrift für Geschichte der Arabisch-Islamischen Wissenschaften 11 (1997), 73-110.

${ }^{49}$ Esta obra, de la que se conservan numerosos manuscritos, fue compuesta en Fez en el 794/13912. Fue objeto, a su vez, de varios comentarios, por ejemplo, el que se encuentra en los fols. 228-334 de esta misma maŷmū'a y cuyo autơr es Abū Zayd 'Abd al-Raḥmān al-Ŷanātī al-Nafāwī. $C f$. King, D. A., A Survey of the Scientific Manuscripts in the Egyptian National Library, Winona Lake, Indiana, 1986, p. 139, n. $^{\circ} \mathrm{F} 26$.

${ }^{50}$ Las coordenadas que ofrece para La Meca son muy usuales (véase fol. 5bis); es curioso que distinga La Meca de la Ka'ba pero, de todos modos, los valores que da para la segunda son también muy usuales. La diferencia de $10^{\circ}$ en la longitud de La Meca viene dada por un intento de ajustar el
} 
Finalmente, se expone la cadena de copistas que han transmitido esta obra, con lo que éste debería ser el quinto eslabón a partir del original. seguido de un dibujo demostrativo de la determinación del watr, el sahm y el qaws y sus respectivos senos y cosenos. Se incluye, en el margen, una pequeña nota biográfica de Ibn al-Bannā' en la que se indica el lugar y fecha de su nacimiento (Marrākuš, 9 o 10 Dū-1-Ḥiŷŷa del 654/28 o 29 de diciembre de 1256) y muerte (Sábado 5 Raŷab del 721/31 de julio de 1321; también se dice que fue enterrado en la puerta de Agmāt, en Marrākuš), por lo que, posiblemente, sea el autor de los fragmentos mencionados.

- Ma 'rifat ŷuz' iŷtimā' al-nayyirayn.

- Faṣl fĩ asbäb al-kusüfāt (del Sol y la Luna).

223-224 - Faltan estos folios aunque, posteriormente, se vuelve a repetir la numeración (que indicamos con asterisco junto al número de folio).

- Anónimo, Fïistijräŷysamt al-qibla. Tres modos distintos de encontrar la qibla seguido de dos versos atribuidos a Aḥmad b. al-Ḥâŷŷ que hacen referencia a la obtención de $a l-\overline{a s s} s^{51}$.

(*) 224 - Tabla de cotangentes (al-zill al-mabsūt, es decir, sombras extensas) para un gnomon igual a 12.

- Tabla de arcos cotangente que permite encontrar la altura del Sol para el zuhr y el 'aşr en función de la altura del Sol en el momento del zawal. La tabla implica que la contangente de la altura del Sol en el momento del zuhr es igual a la cotangente del zawāl más una cuarta parte del gnomon utilizado. Mientras que la cotangente de

Mediterráneo a sus medidas reales. Por último, y refiriéndonos a las coordenadas de Fez, hemos encontrado varias fuentes que ofrecían una $\lambda=24^{\circ}$, pero ninguna daba una $\varphi=23^{\circ}$ (sí de $33^{\circ}$ o $22^{\circ}$ (Ulug Beg), aunque este último parece un error por $32^{\circ}$ ). Cf. Kennedy, 226 y 117-118.

${ }^{51} C f$. fol. 172 de la misma maŷmü'a. 
la altura del Sol, en el momento del 'așr, es igual a la cotangente del zawāl más la longitud del gnomon ${ }^{52}$.

(*) 225 - Tabla de longitudes y latitudes geográficas de 48 ciudades y países tanto orientales como occidentales.

- Mención breve de distancias geográficas entre varias ciudades orientales.

- Rosa de los vientos que hace coincidir los cuatro vientos principales con los puntos cardinales. Incluye, también, una subdivisión en 12 nakbä's ${ }^{53}$.

227 - Tabla de las declinaciones de los fines de los doce signos zodiacales (para una obliciudad de la Eclíptica de $23 ; 30^{\circ}$ ).

- Mención, al margen, de la Rawda de al-Ŷādīrī.

- Lista de láminas de un astrolabio utilizado por «s $\bar{l} d \bar{l}$ Ahmad" que incluye las siguientes: para $\varphi 15 ; 30^{\circ} ; 21^{\circ} \mathrm{Meca} ; 30^{\circ} ; 31^{\circ}$ (principio del clima III); $33^{\circ}$ (punto medio del clima III); $34 ; 30^{\circ} ; 36^{\circ}$ (principio del clima IV); $45^{\circ}$ (principio del clima VI); $66^{\circ}$ (probablemente Trópico de Cáncer); además de una lámina para latitud desconocida, una zarqāl $\bar{y} y a^{54}$, una $\hat{y} \bar{a} m i{ }^{\prime} a^{55}$ y una proyección para el centro de la tierra (latitud $\left.0^{\circ}\right)^{56}$.

228-334 - Abū Zayd 'Abd al-Raḥmān al-Ŷanātī, conocido como al-Nafāwīis7, comentario a la Rawda de al-Ŷādīî̀ ${ }^{-58}$, sin título específico. Parece

52 Véase el artículo «Mīkāt" de D. A. King en $E I^{2}$ VII, p. 28.

${ }^{53} \mathrm{~L}$ os nakba $\overrightarrow{\mathrm{s}}$ son los vientos intermedios entre dos vientos cardinales. $C f$. artículo Rị̣ en $E I^{2}$ VIII, 544-545 (M. Forcada); Abū Ḥāmid al-Garnạțī, al-Mu 'rib 'an ba 'd 'aŷà'ib al-Magrib, Introducción, edición y traducción de I. Bejarano, Madrid, 1991, 206-225.

${ }^{54}$ Sobre la azafea zarqãlīya, véase Puig, R., Los Tratados de construcción y uso de la azafea de Azarquiel, Madrid, 1987.

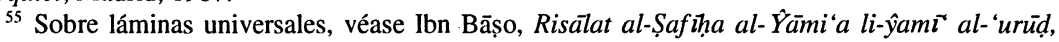
edición crítica, traducción y estudio por Emilia Calvo, Madrid, 1993.

${ }^{56}$ Cf. García Franco, S., Catálogo crítico de astrolabios existentes en España, Madrid, 1945, 176-177.

${ }^{57}$ Mannūnī dice que el manuscrito "538" de la Zāwiya contiene una copia completa de esta obra finalizada en el año 1145/1732-33. Cf. Mannūnī , p. 156; Rénaud I, p. 94; GALS II, p. 218.

${ }^{58}$ Hay varios comentarios a esta Rawda. El primero es el Natä'ij al-afkār fi-šarh rawdat al-azhār, cuyo autor parece haber sido discípulo de al-Habbāk. El segundo es el Qatf al-anwār min rawdat alazhār de Abū Zayd 'Abd al-Raḥmān b. 'Umar b. Aḥmad al-Sūsī al-Ŷazūlī al-Bu'aqīìi, conocido como 
que el autor trabajaba en Fez. El último capítulo está incompleto. De entre las autoridades mencionadas cabe destacar, entre otros, a Ibn al-Raqqām ${ }^{59}$, al-Sabtî ${ }^{60}$, Ibn al-Haytam ${ }^{61}$, Ibn al-Bannā ${ }^{62}$, Ibn Qunfud $^{63}$, al-Ḥabbāk ${ }^{64}$, Abū 'Abd Allāh al-Harawī, Ibn Jaydūr y Muhammad al-Sanūsî́ ${ }^{-65}$.

335-338 - Glosario que contiene 7 voces sin aparente vínculo entre ellas, por ejemplo, käfür y șaḍà. El copista dejó espacio, presumiblemente, para incluir más entradas.

339 - Receta de una infusión hecha a base de agua de rosas y azafrán que debe ser utilizada como tinta para escribir unos versículos coránicos determinados. Posteriormente, este mismo líquido debe ingerirse, en ayunas, el primer jueves del mes antes de la salida del Sol, con el fin de conseguir protección contra el "mal». El copista dice haber tomado esta fórmula de su tío materno 'Abd al-Wāhịid b. Aḥmad al-Ḥasanīí ${ }^{66}$, quien la tomó de Aḥmad b. Abī Ŷu'a al-Wahrānī, quien, a su vez, la tomó del autor, Gānim alQamarī.

340 - Lista de 30 estrellas con indicación del grado de la eclíptica que cruza el meridiano simultáneamente con la estrella, declinación y signo de la misma.

- Tabla con 7 estrellas con las mismas indicaciones que la tabla anterior.

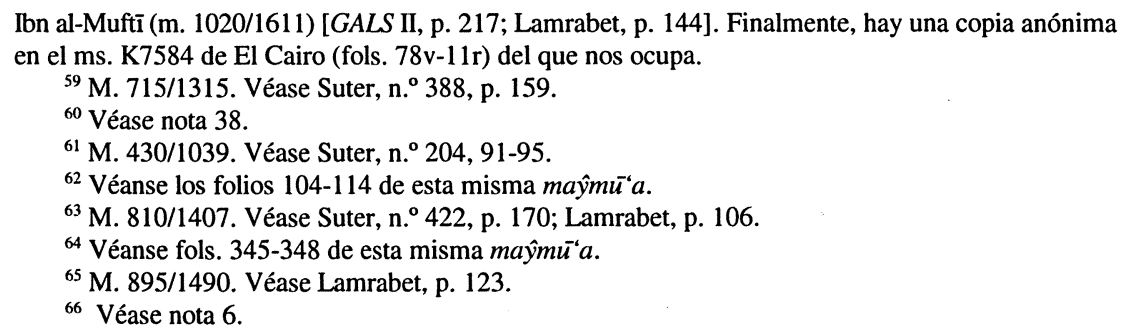


342 - Tabla que permite definir la posición del Sol en las mansiones lunares en función de la fecha del año solar.

343 - Tabla cuadrática de los signos zodiacales para determinar la posición de la Luna ${ }^{67}$.

344 - Tabla que resume el sistema abŷad de numeración.

- Tabla que estructura los doce signos en sus cuatro triplicidades (aire, agua, tierra y fuego) a las que añade sus características astrológicas.

- Siguen unos versos que reiteran lo expuesto en la tabla anterior.

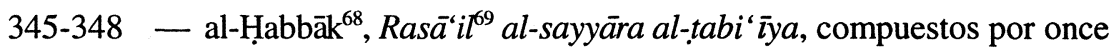
breves capítulos.

349-361 - Tratado anónimo sobre el uso del cuadrante titulado Dikr mā yuhtâŷ̀ ilay-hi min al- 'amal bi-rub' al-dā'ira wa-ma 'rifat aškāli-hā wa-suwari-hā. Consta de una introducción y 33 capítulos $^{70}$.

362-387 - Abū 'Abd Allāh Muhammad b. Salāma b. Ŷa'far b. Aḥmad b. Hakmūn al-Qựā'ī, Kităb al-Šihāb ${ }^{71}$. En nota al margen del primer folio aparece la fecha de muerte de este tradicionista egipcio, 454 (1062).

Los folios 381 y 387 constan, por error, como 181 y 187 , respectivamente.

\footnotetext{
${ }^{67}$ Samsó, J., Las ciencias de los antiguos en al-Andalus, Madrid, 1992, 35-36; Samsó, J., «En torno a los métodos de cálculo utilizados por los astrólogos andalusíes a fines del s. VIII y principios del IX: algunas hipótesis de trabajo", Actas de las II Jornadas de Cultura Árabe e Islámica (1980), Madrid, 1985, p. 516; Castelló, F., «Una tabla cuadrática de los signos zodiacales en un tratado de astronomía árabe», en J. Vernet, ed., Nuevos estudios sobre astronomía española en el siglo de Alfonso X, Barcelona, 1983, 139-141.

${ }^{68}$ Abū 'Abd Allāh Muḥammad b. Aḥmad b. [Abī] Yahyà al-Tilimsānī al-Habbāk (m. 867/14621463). $C f$. Lamrabet, p. 117; Bibliothèque Générale de Rabat ms. D2023; Rénaud 1, p. 89; Suter, n. ${ }^{\circ}$ 435, p. 177; GALS II, p. 365.

${ }^{69}$ Mannūnī (p. 156) lee Risălat.

${ }^{70}$ Mannūnī , p. 156.

${ }^{71}$ GAL I, p. 343; GALS I, 584-585.
} 
388-406 - Yaḥyà b. Šaraf al-Nawaw $\overline{1}^{-72}, K i t a ̄ b$ al-arba' ina had ițan. Obra que contiene una introducción, cuarenta y dos had îtes y un capítulo final, donde se ofrecen aclaraciones sobre las dudas que se puedan tener sobre los had it $\underline{\text { tes }}$ citados. Finalmente, hay un apartado donde se explica el concepto de transmisión que tiene el autor. Fechado en el 18 de $\underline{D} \bar{u}-l-h i \hat{y} \hat{y} a$ (la cifra que indica el año es ilegible).

407-411 - Cuatro jutbas en prosa rimada de 'Abd al-Wāḥid b. Aḥmad alHasani ${ }^{-73}$, tres de las cuales deben pronunciarse antes de la yalsa y una cuarta que debe ser leída después.

411-412 - Una jutba en prosa rimada del alfaquí Muḥammad b. Balqāsim alHasanī, tío paterno del copista. En el folio 425 de la misma maŷmū'a aparece su fecha de muerte: $988(1580)^{74}$.

413-416 - Qașìda marțīya que el copista dedica a su tío, 'Abd al-Wāhid b. Ahmmad b. Muḥammad b. al-Ḥasan al-Ḥasanī (autor de las juṭas de los fols. 407-411) ${ }^{75}$. El poema consta de 73 versos, 4 de los cuales están tachados.

La numeración de los folios salta, por error, del 413 al 415.

416 - Dos breves qașìdas, cuyo autor es el mismo copista de la maŷmū'a, sobre los "nombres» del león (asmä’ al-asad). El texto es de difícil lectura ya que el final del folio está muy deteriorado.

417-424 - Glosario de sinónimos que incluye voces muy variadas sin orden aparente. Por ejemplo, asad, jafiff y šams.

425 - Listado de alfaquíes y cadíes con mención de su fecha de muerte ${ }^{76}$ :

\footnotetext{
${ }^{72}$ El nombre completo de este tradicionista, muerto en el año 676/1277, es Muhyȳ al-Dīn Abū Zakarīyā Yahyyà b. Šaraf b. Mira b. Hasan b. Husayn b. Muḥammad b. Ỳum'a b. Hizām al-Nawawī. Cf. GAL I, p. 394; GALS I, p. 680.

${ }^{73}$ Véase nota 6. Mannūnī (p. 156) añade al-Anșārī.

${ }^{74}$ Mannūnī (p. 156), basándose en la Ŷadwat al-iqtibās de Ibn al-Qāộ̄, añade el gentilicio alSiŷilmāsī y corrobora que murió en Marrākuš el 988.

${ }^{75}$ Véase nota 6. $C f$. Mannūnī , p. 156.

${ }^{76}$ Mannūnī , p. 157.
} 
- [Muḥammad b. Abī l-Qāsim al-Ḥasanī, muerto el jueves 16 de Muharram del 988 (3 de marzo de 1580) en Marrākuš. Dirigió la oración funeraria su primo 'Abd al-Wāḥid b. Aḥmad b. Muhammad b. al-Ḥasan al-Ḥasanī al-Šarīf.

- el cadí Sa ‘īd b. 'Alī (sin fecha).

- el cadí 'Abd al-Wāhid b. Ahmad al-Humaydī (sin fecha) $)^{77}$.

- el cadí Qāsim b. 'Alī al-Šậtibī, muerto un viernes de Ša 'bān del 1002 (1593-94) en Marrākuš. Dirigió la oración funeraria alamīr al-mu'minin Ả Abūl-'Abbās Aḥmad al-Manșūir ${ }^{78}$. Fue cadí de Marrākuš 37 años y se dice que murió envenenado.

En el margen del folio aparecen otras anotaciones biográficas:

— 'Umar b. Aḥmad b. al-Qāsim al-Šarīf, padre del copista, muerto en 1005 (1596-1597).

- Fecha de muerte de la madre del copista, 1006 (1597-1598).

- Muhammad b. 'Abd al-Wāḥid ? Aḥmad b. ?, muerto un miércoles de Šawwāl del 100[8?].

- Muhammad b. 'Umar, hermano del copista, muerto a fines de Ŷumadà II del 1010 (1601-1602).

— 'Ā'iša bint 'Abd ?, muerta el jueves 18 de Dū-l-Qa'da del 10?? (posiblemente el 1010/1601 o 1013/1604).

- Muḥammad b. Abī Bakr (sin fecha).

- imām al-Birzalī, muerto en el año 804 /1401-02) a los 103 años.

426

- 'Abd al-Wāḥid b. Aḥmad al-Šarīi al-Ḥasanī murió, a los 70 años, el 26 de Raŷab del 1003 (el copista da la equivalencia correcta del día y mes, no del año, del calendario juliano, 28 de marzo [del 1595]).

- Muhammad b. Mūsà al-Aysī, murió el sábado 21 de Rabī‘ II del 1004 (el copista también ofrece la equivalencia del día y mes, 12 de diciembre $\left.{ }^{79}[1595]\right)$. p. 142 .

${ }^{77}$ Según Ibn al-Qāḍī murió el año 1003/1594-95. Cf. Ibn al-Qāọī , Durrat al-hîŷăl III, n. ${ }^{\circ}$ 1098,

${ }^{78}$ Aḥmad al-Manșưr al-Dahabī reinó entre el 986/1578 y el 1012/1603. Véase Laroui, A., Historia del Magreb, Madrid, 1994, 247-249 y 394; $E I^{2}$ VIII, 744-745 (C. de la Véronne).

${ }^{79}$ En realidad, 13-14. 
- Muḥammad b. Aḥmad, hermano de 'Abd al-Wāhid al-Hasanī, murió el miércoles 16 de Raŷab del 1005 (23 de febrero de 1597), a los 76 años de edad.

- Ibrāhīm b. Muhammad al-Šawī murió el martes 27 de Ša ‘bān del 1005 (5 de abril de 1597).

Margen inferior:

- Hasan ? al-Ḥasan̄̄, nació el jueves 5 de Rabī‘ I del 95? y murió el 12 de Ŷumādà II del [9]82 (29 de septiembre de 1574).

- 'Abd ? al-Ḥasan̄i, nació el año 951 (1544-45) y murió el 980 (1572-73).

Margen derecho:

— Āmina bint ? al-Šarīfa, esposa de 'Abd al-Wāḥid b. Aḥmad al-Šarīf al-Ḥasanī, murió el año 1004 (1595-96).

- Mención de dos batallas (contemporáneas al copista):

- La primera está fechada el viernes 7 de Ša ‘bān del 1015 (en el margen superior da la equivalencia del día y mes pero no del año: 28 de noviembre [de 1606]). Tuvo lugar entre al-amīr almu'min in Abū Fāris b. Aḥmad ${ }^{80}$ y su sobrino 'Abd Allāh b. Aḥmad. El combate tuvo lugar cerca de Marrākuš y Abū Fāris huyó derrotado.

- La segunda fue el 16 de Ša 'bān, que según el copista equivale al 26 de noviembre sin mencionar el año, pero de su equivalencia deducimos que se trata del año siguiente, el 1016/1607. Se enfrentaron el vencedor de la batalla anterior, 'Abd Allāh, y alamīr al-mu'min̄̄n Zaydān b. Aḥmad ${ }^{81}$ cerca de Marrākuš.

\footnotetext{
${ }^{80}$ Abū Fāris b. Aḥmad, hijo de al-Manșūr al-Dahabī (véase fol. 425) perdió el poder de Marrākuš ante Mawlāy 'Abd Allāh, hijo de al-Ma'mūn, en el año 1015/1606. Véase $E I^{2}$ VIII, p. 745.

${ }^{81}$ Hijo de al-Manșūr al-Dahabī , Zaydān, que reinó del 1012/1603 al 1028/1618, recuperó la ciudad de Marrākuš que su hermano Abū Fāris había perdido. Cf. EI ${ }^{2}$ VIII, p. 745; Laroui, A., Historia del Magreb, p. 394.
} 


\section{RESUMEN}

En este artículo se lleva a cabo una descripción detallada del ms. 80 de la Zāwiya Ḥamzawīya (Marruecos). Es un maŷmü recopilado, en su mayor parte, por un mismo copista (que vivió a caballo entre los siglos XVI y XVII) del que desconocemos su nombre completo, aunque no el de su padre: 'Umar b. Aḥmad b. Abī-l-Qāsim al-Šarīf. El maŷmu" contiene 427 folios con textos de variado contenido, predominando los de carácter astronómico. Entre otras obras, incluye una copia del Kitäbfi-l- 'amal bi-l-asturläb de Abū-l-Șalt de Denia; el Kitäb min 'ilm al-awqāt bi-l-hiisāb de Ibn al-Bannā de Marrākuš; el Tanbīh al-anām 'alà mā yahdutu fī ayyām al-'ām de al-Ŷādīīī, así como su Urŷuza Rawdat al-Azhār; y la única copia del Kitāb al-nuŷūm de 'Abd. al-Mālik b. Ḥabīb.

\section{ABSTRACT}

In this article we have carried out a detailed description of ms. 80 of the Zāwiya Hamzawiya (Morocco). This is a majmū compiled, most of it, by a single copist (who lived between the $16^{\text {th }}$ and $17^{\text {th }}$ centuries). We do not know his name, although his father's name was 'Umar b. Aḥmad b. Abī-l-Qāsim al-Sharīf. The majmü' has 427 pages of miscellaneous contents, even though most of them are of astronomical nature. Among other works, it includes Abū-l-Șalt's of Denia Kitāb fī-l-'amal bi-l-asturlāb; Ibn al-Bannā alMarrākushī's Kitäb min 'ilm al-awqāt bi-l-hisäb; al-Jādīīi's Tanbĭh al-anām 'alà mā yahduthu fĩ ayyām al-'äm, as well as his Urjuza Rawdat al-Azhär; and Kitäb al-nujūm of 'Abd al-Mālik b. Habīib extant only in this manuscript. 